\title{
Occurrence of a mosquito vector in bird houses: Developmental consequences and potential epidemiological implications
}

\author{
Hamady Dienga,b,*, Rahimah Binti Hassan ${ }^{a}$, Ahmad Abu Hassan ${ }^{a}$, Idris Abd Ghanic \\ Fatimah Bt Abang ${ }^{\mathrm{d}}$, Tomomitsu Satho ${ }^{\mathrm{e}, \mathrm{f}}$, Fumio Miake ${ }^{\mathrm{e}, \mathrm{f}}$, Hamdan Ahmad $^{\mathrm{a}}$, \\ Yuki Fukumitsu ${ }^{\mathrm{e}, \mathrm{f}}$, Nur Aida Hashim ${ }^{\mathrm{e}, \mathrm{f}}$, Wan Fatma Zuharah ${ }^{\mathrm{a}}$, Nur Faeza Abu Kassim ${ }^{\mathrm{a}}$, \\ Abdul Hafiz Ab Majid ${ }^{a}$, Rekha Selvarajoo ${ }^{g}$, Cirilo Nolasco-Hipolito ${ }^{d}$, \\ Olaide Olawunmi Ajibola ${ }^{\mathrm{d}}$, Andrew Alek Tuen ${ }^{\mathrm{b}}$
}

a School of Biological Sciences, Universiti Sains Malaysia, Penang, Malaysia

${ }^{\mathrm{b}}$ Institute of Biodiversity and Environmental Conservation (IBEC), Universiti Malaysia Sarawak, Kuching, Kota Samarahan, Malaysia

${ }^{\mathrm{c}}$ Faculty of Science and Technology, Universiti Kebangsaan Malaysia, Bangi, Malaysia

${ }^{d}$ Faculty of Resource Science and Technology, Universiti Malaysia Sarawak, Kota Samarahan, Malaysia

e Faculty of Pharmaceutical Sciences, Fukuoka University, Japan

${ }^{\mathrm{f}}$ School of Food Science and Technology, Universiti Malaysia Terengganu, Kuala Terengganu, Malaysia

${ }^{g}$ School of Social Sciences, University Utara Malaysia, Kedah Darul Aman, Malaysia

\section{A R T I C L E I N F O}

\section{Article history:}

Received 22 October 2014

Received in revised form

29 December 2014

Accepted 7 January 2015

Available online 21 January 2015

\section{Keywords:}

Bird feces

Aedes larvae

Nutrient

Development

Adult life traits

Epidemiological significance

\begin{abstract}
A B S T R A C T
Even with continuous vector control, dengue is still a growing threat to public health in Southeast Asia. Main causes comprise difficulties in identifying productive breeding sites and inappropriate targeted chemical interventions. In this region, rural families keep live birds in backyards and dengue mosquitoes have been reported in containers in the cages. To focus on this particular breeding site, we examined the capacity of bird fecal matter (BFM) from the spotted dove, to support Aedes albopictus larval growth. The impact of BFM larval uptake on some adult fitness traits influencing vectorial capacity was also investigated. In serial bioassays involving a high and low larval density (HD and LD), BFM and larval standard food (LSF) affected differently larval development. At HD, development was longer in the BFM environment. There were no appreciable mortality differences between the two treatments, which resulted in similar pupation and adult emergence successes. BFM treatment produced a better gender balance. There were comparable levels of blood uptake and egg production in BFM and LSF females at LD; that was not the case for the HD one, which resulted in bigger adults. BFM and LSF females displayed equivalent lifespans; in males, this parameter was shorter in those derived from the BFM/LD treatment. Taken together these results suggest that bird defecations successfully support the development of Ae. albopictus. Due to their cryptic aspects, containers used to supply water to encaged birds may not have been targeted by chemical interventions.
\end{abstract}

(c) 2015 Elsevier B.V. All rights reserved.

\section{Introduction}

Dengue has become a major international public health concern, and outbreaks can now occur almost anywhere and at any time (WHO, 2014). Previously considered as the primary vector, Aedes aegypti has been joined by Aedes albopictus in many parts of the world (Rochlin et al., 2013). This latter species has been suggested

\footnotetext{
* Corresponding author at: Faculty of Resource Science and Technology-IBEC, Universiti Malaysia Sarawak, Kuching, Malaysia. Tel.: +60 103887158.

E-mail address: hamachan1@yahoo.com (H. Dieng).
}

to have played roles in recent outbreaks of dengue (Rezza, 2012; Das et al., 2013), a disease that kills more people than any other mosquito-borne virus globally (Gubler, 2004; Farrar et al., 2007). The main strategy to control dengue vectors is the use of insecticides through the application of larvicides and space spraying (WHO, 2010). Apart from increased resistance to the main families of insecticides (Dia et al., 2012), the control of dengue vectors is complicated by the existence of cryptic larval habitats that can be highly productive (Gonzalez et al., 2007; Arana-Guardia et al., 2014; Barrera et al., 2014). Ae. albopictus has been reported in cryptic habitats (Lam et al., 2010). According to Russell and colleagues, when secretive breeding sites are present, but unknown, 